\section{Apolipoprotein F}

K. J. Lackner ${ }^{1}$ und D. Peetz ${ }^{2}$

${ }^{1}$ Institut für Klinische Chemie und Laboratoriumsmedizin, Universitätsmedizin Mainz, Mainz, Deutschland

${ }^{2}$ Institut für Labormedizin, Helios Klinikum Berlin-Buch,

Berlin, Deutschland

Synonym(e) ApoF

Englischer Begriff apolipoprotein F
Definition ApoF ist ein Apolipoprotein der High Density Lipoproteine (s. $>$ High Density Lipoprotein).

Beschreibung ApoF ist ein ca. $31 \mathrm{kDa}$ schweres Protein, das als 308 Aminosäuren langes Proprotein in der Leber synthetisiert wird. Im Plasma an HDL gebunden. Funktion des Proteins ist nicht geklärt.

\section{Literatur}

Day JR, Albers JJ, Gilbert TL et al (1994) Purification and molecular cloning of human apolipoprotein F. Biochem Biophys Res Commun 203:1146-1151 